\title{
Epidemiological Concepts Regarding Disease Monitoring and Surveillance
}

\author{
By Jette Christensen \\ Danish Veterinary Laboratory, Bülowsvej 27, DK-1790 Copenhagen V, Denmark. Phone + 45353001 00, Fax \\ + 45353001 20, Email: jc@svs.dk
}

\begin{abstract}
Definitions of epidemiological concepts regarding disease monitoring and surveillance can be found in textbooks on veterinary epidemiology. This paper gives a review of how the concepts: monitoring, surveillance, and disease control strategies are defined. Monitoring and surveillance systems (MO\&SS) involve measurements of disease occurrence, and the design of the monitoring determines which types of disease occurrence measures can be applied. However, the knowledge of the performance of diagnostic tests (sensitivity and specificity) is essential to estimate the true occurrence of the disease. The terms, disease control programme (DCP) or disease eradication programme (DEP), are defined, and the steps of DCP/DEP are described to illustrate that they are a process rather than a static MO\&SS.
\end{abstract}

disease control programme, disease eradication programme.

\section{Introduction}

The Nordic countries have a longstanding tradition of animal disease control (Pedersen, 1996). For decades, the Nordic countries have been free of the OIE list A diseases apart form recent outbreaks of Newcastle Disease and an outbreak of Foot and Mouth disease in the early 1980s. During the last decades, other diseases as Aujezsky's disease and IBR have been successfully combated. Therefore, the accumulated knowledge of animal disease control in the Nordic countries is extensive. Experts in different disciplines of veterinary science (e.g. practice, virology, and bacteriology) have gained experience in disease control and co-operation. Veterinary epidemiology is the science that describes the distribution of disease and health in populations (the what, where, when, and how much of disease) and the investigation of the determinants for the disease occurrence (the why of disease). Therefore, veterinary epidemiology is an effective tool in the course of an animal disease control campaign, and epidemiology has already been applied in animal disease control in the Nordic countries. Epidemiologists contribute with design of monitoring and surveillance systems and analyses of data from them. However, for the successful cooperation among disciplines in the combat of diseases it is important to establish a common terminology. This paper will give an epidemiologist's terminology of some concepts applied in the animal disease control.

\section{Definition of concepts}

Definitions on epidemiological concepts regarding disease monitoring and surveillance can be found in textbooks on veterinary epidemiology (Martin et al., 1987; Thrusfield, 1986; and Noordhuizen et al., 1997). It is generally accepted that both disease monitoring and surveillance involve the continuous collection of data (Table 1). Animal disease monitor- 
Table 1. Definitions of disease monitoring and surveillance found in three textbooks on veterinary epidemiology.

\begin{tabular}{|c|c|c|}
\hline Textbooks & $\begin{array}{l}\text { Definitions of } \\
\text { Monitoring }\end{array}$ & Surveillance \\
\hline $\begin{array}{l}\text { Martin et al. } 1987 \\
\text { (page 259) }\end{array}$ & $\begin{array}{l}\text { Animal disease monitoring } \\
\text { describes the ongoing efforts } \\
\text { directed at assessing the health } \\
\text { and disease status of a given } \\
\text { population. }\end{array}$ & $\begin{array}{l}\text { The term "disease surveillance" is used } \\
\text { to describe a more active system and } \\
\text { implies that some form of directed } \\
\text { action will be taken if the data indicate } \\
\text { a disease level above a certain threshold. }\end{array}$ \\
\hline $\begin{array}{l}\text { Thrusfield, } 1995 \\
\text { (page 22) }\end{array}$ & $\begin{array}{l}\text { Monitoring is the making of } \\
\text { routine observations on health, } \\
\text { productivity and environmental } \\
\text { factors and the recording and } \\
\text { transmission of these observations. }\end{array}$ & $\begin{array}{l}\text { Surveillance is a more intensive } \\
\text { form of data recording than monitoring. }\end{array}$ \\
\hline (page 358 and 360 ) & $\begin{array}{l}\text { The routine collection of information } \\
\text { on disease, productivity, and other } \\
\text { characteristics possibly related to } \\
\text { them in a population. }\end{array}$ & $\begin{array}{l}\text { An intensive form of monitoring (q.v.), } \\
\text { designed so that action can be taken } \\
\text { to improve the health status of a population, } \\
\text { and therefore frequently used in disease } \\
\text { control campaigns. }\end{array}$ \\
\hline $\begin{array}{l}\text { Noordhuizen et al., } \\
1997 \\
\text { (page 379) }\end{array}$ & $\begin{array}{l}\text { Monitoring refers to a continuous, } \\
\text { dynamic process of collecting data } \\
\text { about health and disease and their } \\
\text { determinants in a given animal } \\
\text { population over a defined time } \\
\text { period (descriptive epidemiology). }\end{array}$ & $\begin{array}{l}\text { Surveillance refers to a specific } \\
\text { extension of monitoring where obtained } \\
\text { information is utilised and measures } \\
\text { are taken if certain threshold values } \\
\text { related to disease status have been passed. } \\
\text { It, therefore, is part of disease control } \\
\text { programmes. }\end{array}$ \\
\hline
\end{tabular}

ing describes the ongoing efforts directed at assessing the health and disease status of a given population. The disease can be a specific infectious disease or diseases/health in general whereas the efforts are the routine recording, analyses and distribution of information related to the disease (or health).

The term disease surveillance is used to describe a more active system and implies that some form of directed action will be taken if the data indicate a disease level above a certain threshold. Therefore, disease surveillance is made up by at least three components: (1) a defined disease monitoring system, (2) a predefined disease intervention strategy (directed ac- tion), and (3) a defined threshold of disease frequency.

Data collection is the core of disease monitoring and surveillance systems (MO\&SS) and whenever data are used the data quality is of great concern. As with any other data collection if the data on disease are collected accurately and representatively and the MO\&SS is designed to monitor the disease the monitoring or surveillance may be referred to as active (primary data are collected). Passive monitoring or surveillance is then referred to when data collected for other purposes (existing or secondary data) are used.

With this definition strictly interpreted an active 
Table 2. Definitions of disease control strategies found in three textbooks on veterinary epidemiology.

\begin{tabular}{|c|c|c|}
\hline Textbooks & Prevention & Eradication \\
\hline $\begin{array}{l}\text { Martin et al. } 1987 \\
\text { (page } 250 \text { ) }\end{array}$ & $\begin{array}{l}\text { Those measures designed to exclude } \\
\text { disease from an unaffected population. }\end{array}$ & $\begin{array}{l}\text { The efforts to eliminate selected } \\
\text { organisms from a defined area. }\end{array}$ \\
\hline $\begin{array}{l}\text { Thrusfield, } 1995 \\
\text { (page 337) }\end{array}$ & & $\begin{array}{l}\text { Commonly in veterinary medicine, } \\
\text { eradication refers to the regional } \\
\text { extinction of an infectious agent. }\end{array}$ \\
\hline $\begin{array}{l}\text { Noordhuizen et al., } \\
1997 \\
\text { (page 295) }\end{array}$ & \multicolumn{2}{|c|}{$\begin{array}{l}\text { Eradication and prevention applies to the highly infectious, monocausal epidemic } \\
\text { diseases threatening large areas of the EU, or causing problems for human beings, } \\
\text { the zoonoses or foodborne infections. }\end{array}$} \\
\hline
\end{tabular}

MO\&SS is perhaps very rarely seen at a regional or national level because accurate and representative sampling is very costly. Once a MO\&SS for one specific disease and animal species is set up, the same sampling scheme is often used to monitor other diseases. Then strictly, the MO\&SS may be active only with regard to the first disease - for all other diseases the MO\&SS could be passive.

Sometimes the term, passive monitoring or surveillance reflects that no actual sampling is done (e.g. the reporting of clinical suspicion of notifiable diseases). Then active monitoring or surveillance is a system where any type of sampling is done. With the latter definition most MO\&SS would be active.

Disease monitoring can lead to and surveillance systems include disease control strategies. There is a general agreement that the control strategies can be classified as prevention, control, and eradication (Table 2). The term prevention is applied to those measures designed to exclude disease from an unaffected population. Control is associated with the efforts directed toward reducing the frequency of existing disease to levels biologically and/or economically justifiable or otherwise of little consequence. Eradication describes the efforts to eliminate selected organisms from a defined population. Animal species and location (herd, region or country) define the population.

One or more interventions may be combined to an intervention strategy and employed in a DCP to reduce disease occurrence (Table 3 ). The choice of intervention strategy depends on the situation (e.g. disease prevalence, biological, economical, political, social conditions) and the objective of the DCP (or DEP). Some of the more drastic interventions like stamping out and depopulation/repopulation clearly aim at eradication while others (e.g. improvement of management) aim at reduction of disease.

Now we can define the term disease control (or eradication) programme. A disease control programme (DCP) is the combined system of monitoring and surveillance, disease control strategies, and intervention strategies that over a prolonged period of time are employed to reduce the frequency of a specific disease. A disease eradication programme (DEP) is a special case of a DCP where the objective of the programme is to eliminate a specific disease (organism). For the remainder of the paper the term DCP will be used, unless it refers to DEP specifically.

Following these definitions of DCP (and DEP), the dynamic aspect of programmes is indicated. Both the MO\&SS and the disease control ef- 
Table 3. Possible interventions in disease control programmes. One or more interventions can be combined in an intervention strategy.

\begin{tabular}{|c|c|}
\hline Type of intervention & Intervention \\
\hline Slaughter & $\begin{array}{l}\text { Stamping out } \\
\text { Depopulation/repopulation } \\
\text { Test and slaughter } \\
\text { Culling }\end{array}$ \\
\hline $\begin{array}{l}\text { Reduction } \\
\text { of contact }\end{array}$ & $\begin{array}{l}\text { Quarantine } \\
\text { Movement restrictions } \\
\text { All in all out } \\
\text { (batch production) }\end{array}$ \\
\hline Chemical use & $\begin{array}{l}\text { Preventive or strategic } \\
\text { treatment } \\
\text { Therapeutic treatment } \\
\text { Disinfection } \\
\text { Pesticides }\end{array}$ \\
\hline $\begin{array}{l}\text { Modification } \\
\text { of host resistance }\end{array}$ & $\begin{array}{l}\text { Vaccination } \\
\text { Genetic resistance }\end{array}$ \\
\hline $\begin{array}{l}\text { Environment and or } \\
\text { management control }\end{array}$ & $\begin{array}{l}\text { Improved husbandry } \\
\text { Feeding } \\
\text { Education } \\
\text { Biological control }\end{array}$ \\
\hline Doing nothing & \\
\hline
\end{tabular}

forts can evolve over time to adjust to changing circumstances (e.g. disease occurrence, biological, political, economical, or social). We will return to the dynamics of a DCP in the next section.

Whether the DCP aims to control or eradicate a disease, it will provide measurements of disease occurrence. The usual methods of measuring disease occurrence (incidence, prevalence, risk, and incidence density) may be applied depending on the data quality, and what data are available. The most serious limitation of the data is not so often the data on the cases (nominator), but the information on noncases (denominator), which is important for the choice of method for measurement of disease fre- quency. A lengthy discussion on the merits of the four methods of disease measurement is beyond the scope of this paper but the definitions will be briefly mentioned.

If very detailed information on new cases and population at risk is available, the incidence density (rate at which new cases occur in the population at risk) may be calculated. This requires an ongoing monitoring of new cases and population at risk, which means recording of all cases when they occur (and recover to be at risk again) but also all entries and exits of the population. When less detailed information is available, prevalence (proportion of cases in the population) is usually calculated. The only data needed are the number of cases (all existing cases) and noncases in the population at a point in time. The prevalence is typically applied in regional or national programmes or when the exact onset of disease is not known. Sometimes only information on cases is available, and then incidence (number of cases) can be reported. The incidence makes comparisons among populations impossible. If information on new cases over a period in a cohort of noncases (at the start of the period) is available, the risk (or cumulative incidence) of acquiring the disease over a period can be calculated. Changes in risk over time can be difficult to interpret and risk is therefore more suitable for disease frequency measurement in risk factor studies.

\section{Dynamics of disease control programmes}

The dynamics of a disease eradication programme become clear when the steps of a typical programme are described (Figure 1). When a disease is not present or has not been identified as a problem in a population, it will not be actively monitored (no sampling for diagnostic tests for the specific disease). However, the general awareness of clinical disease is a passive monitoring of the population for this disease and clinical disease may cause detection of the 

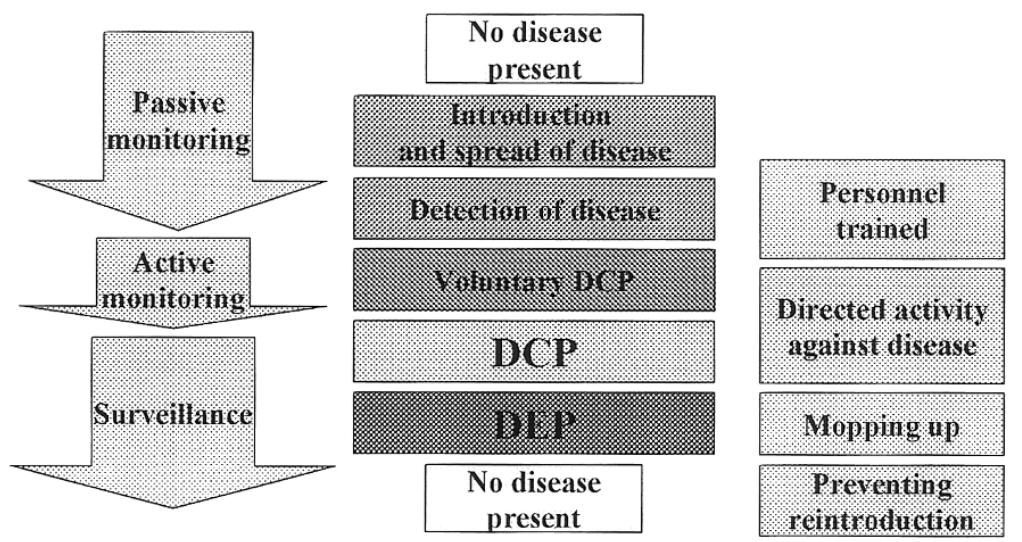

Figure 1. The steps when a voluntary disease control programme develop over a disease control programme (DCP) into a disease eradication programme (DEP).

disease. During this step the disease may be introduced, spread in the population, and be recognised as a potential problem (e.g. adverse effect on production or human health risk).

The monitoring may become active when the first assessment of the size of the problem (economic impact or human health risk) is implemented. Knowledge of the disease is acquired and the training of personnel (veterinarians and farmers) will take place in this step. Some farmers may start to combat the disease in voluntary control programmes and this will provide valuable knowledge. If the disease is considered a serious threat to human health (multiresistant Salmonella Typhimurium DT 104) or has major economic impact (outbreak of Swine Vesicular Disease in an exporting country), actions to prevent further spread of disease may be applied even at this early stage to keep the prevalence low. The aim of this effort is to have the option to proceed directly to DEP. Otherwise this step should ideally last long enough to establish the adequate expertise to design an effective DCP.

At this point, the prevalence (and biology) of the disease will determine if eradication is the immediate objective (next step) or if a disease control step to reduce the prevalence needs to be implemented first. Unless the disease is sporadic, the next feasible step will be a DCP. Here, systematic activities directed against the disease are implemented in a surveillance system. The monitoring is to be targeted at the disease, thresholds for interventions against the disease defined, and predefined interventions are to be implemented to reduce disease occurrence. From this point onwards, it is important to include the total population (herd, region or country). In national programmes, this is when legislation is put into force.

The DCP may evolve into a DEP. When the prevalence is low and eradication may be an option, the elimination of the infectious agent can start. The efforts to detect the last cases can be extensive and testing the population free of the disease usually ends the DEP (Willeberg 1999). Now after the end of the DEP, interventions to reduce the risk of reintroduction (e.g. quarantine) should be continued or implemented. Preferably, some surveillance system should be 
kept in place to detect reintroduction, to limit the spread of the disease after an introduction, and to document freedom from disease.

\section{Discussion}

In DCP, decisions with substantial impact (economical or social) may depend on estimates of disease frequency, say prevalence. Therefore, it can be important to estimate the true prevalence. How accurate the apparent prevalence (AP) is compared to the true prevalence (TP), depends on the performance of the diagnostic test(s) used. Estimates of sensitivity (Se, proportion of test positive in a truly positive population) and specificity ( $\mathrm{Sp}$, proportion of test negative in a truly negative population) will make it possible to estimate the true prevalence. For a diagnostic test with $\mathrm{Se}=0.5$ and $\mathrm{Sp}=1$ (e.g. bacteriological examination) and $\mathrm{AP}=0.2$ the true prevalence is be 0.4. $(\mathrm{TP}=(\mathrm{AP}-(1-\mathrm{Sp})) /$ $(\mathrm{Se}+\mathrm{Sp}-1))$. This example demonstrates how disease prevalence can be grossly underestimated if the test performance is unaccounted for. For a more detailed review of diagnostic test performance at individual level or herd level, the reader is referred to the literature.

The steps in DCP/DEP illustrate that a programme should be seen as a process rather than a static MO\&SS. It is unlikely that an eradication (or control) can be successful, unless adjustments to monitoring, intervention thresholds and types of intervention are made to reflect the changing situation.

\section{References}

Martin SW, Meek AH, Willeberg P: Veterinary epidemiology. Principles and methods. IOWA State University Press / Ames, Iowa, USA. 1986.

Noordhuizen JPTM, Frankena K, van der Hoofd CM, Graat EAM: Application of quantitative methods in veterinary epidemiology. Wageningen Pers, Wageningen, The Netherlands. 1997.

Pedersen KB: The tradition of animal disease control in the Nordic countries compared to the rest of Europe. Acta vet. scand. 1996, Suppl. 90, 9-16.

Thrusfield M: Veterinary epidemiology. 1995. Blackwell Science Ltd. Oxford, UK.1995

Willeberg P: Sampling to detect rare disease. Acta vet. scand. 1999 same issue. 